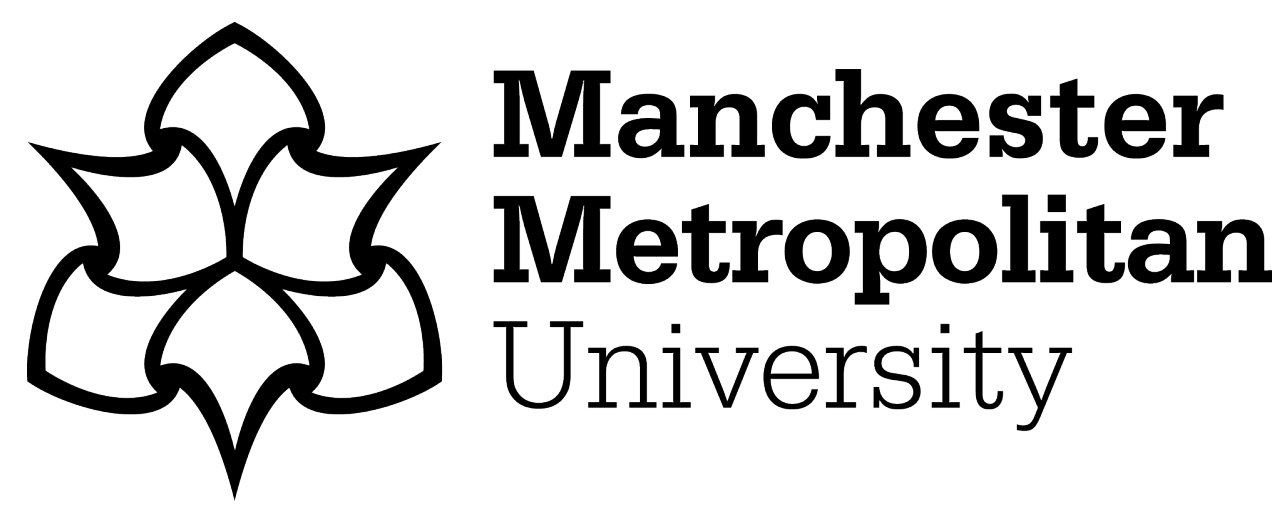

Leal Filho, W and Morgan, EA and Godoy, ES and Azeiteiro, UM and BacelarNicolau, P and Veiga Ávila, L and Mac-Lean, C and Hugé, J (2018)/mplementing climate change research at universities: Barriers, potential and actions. Journal of Cleaner Production, 170. pp. 269-277. ISSN 0959-6526

Downloaded from: http://e-space.mmu.ac.uk/621028/

DOI: https://doi.org/10.1016/j.jclepro.2017.09.105

Please cite the published version 


\title{
Implementing Climate Change Research at Universities: Barriers, Potential and Actions
}

Walter Leal Filho ${ }^{1}$, Edward A. Morgan ${ }^{2,3 *}$, Eric S. Godoy ${ }^{4}$, Ulisses M Azeiteiro ${ }^{5}$, Paula Bacelar-Nicolau ${ }^{7}$, Lucas Veiga Ávila ${ }^{7}$, Claudia Mac-Lean ${ }^{8}$, Jean Hugé ${ }^{9}$

${ }^{1}$ School of Science and the Environment, Manchester Metropolitan University, Chester Street, Manchester M1 5GD, UK w.leal@mmu.ac.uk

${ }^{2}$ Cities Research Institute, Griffith University, 170 Kessels Road, Brisbane, Queensland 4111, Australia ed.morgan@griffith.edu.au

${ }^{3}$ Climate Change Response Program, Griffith University, Parklands Drive, Southport Queensland 4222, Australia

${ }^{4}$ Department of Social Science and Cultural Studies, Pratt Institute, 200 Willoughby Avenue, Brooklyn NY, 11205, USA egodoy2@pratt.edu

${ }^{5}$ Department of Biology \& CESAM Centre for Environmental and Marine Studies, University of Aveiro, 3810-193 Aveiro, Portugal ulisses@ua.pt

${ }^{6}$ Unversidade Aberta, Portugal \& Centre for Functional Ecology, Universidade de Coimbra, Portugal pnicolau@uab.pt

${ }^{7}$ Federal University Of Santa Maria - UFSM, Brazil.admlucasveiga@gmail.com

${ }^{8}$ Office of Engineering for Sustainable Development, University of Chile, Beauchef 850, Santiago 837048, Chile cmaclean@ing.uchile.cl

${ }^{9}$ Systems Ecology \& Resource Management Unit, Université Libre de Bruxelles. Avenue Franklin Roosevelt 50, 1050 Brussels, Belgium.

${ }^{10}$ Plant Biology \& Nature Management Unit, Vrije Universiteit Brussel. Pleinlaan 2,1050 Brussels, Belgium.

${ }^{11}$ KLIMOS-ACROPOLIS Policy Support Platform. Brussels, Belgium Jean.Huge@ulb.ac.be

\begin{abstract}
Many universities around the world have been active centres of climate change research. However, there are a number of barriers to climate change research, stemming both from the nature of the research and the structure of institutions. This paper offers an overview of the barriers which hinder the handling of matters related to climate change at institutions of higher education (IHEs), and reports on an empirical study to investigate these barriers using a global survey of higher education institutions. It concludes by proposing some steps which could be followed, with a view to making climate change more present and effective in university research and teaching. These include changing approaches to research, outreach and teaching to better support action on climate change.
\end{abstract}

(8110 words, including references)

\section{Introduction}


Many universities, or more generally institutions of higher education (IHEs), around the world have been centres of climate change research. However, there are a number of barriers to climate change research, related to both the nature of the research and the design of institutions. This paper uses a theoretical and empirical approach to identify those barriers and highlight the potential of IHEs to improve climate change research. It proposes possible actions for both those researching climate change at IHEs and the managers and administrators in IHEs. These suggestions will help universities to better support climate change research and, more importantly, support significant action on climate change.

The barriers to climate change research in IHEs are well documented in the literature and are discussed briefly below to provide some context of the issues. The following section then discusses how considering the moral dimension of climate change can highlight the potential for IHEs to better address the climate change challenge. The empirical work detailed in the next sections reveals how universities face these barriers and seek to address them. The final section draws the theoretical and empirical studies together to produce future actions for universities and other IHEs to expand their role is addressing climate change.

To begin with, it should be noted that climate change can be regarded as a 'wicked problem', as it is both complex and uncertainty, and lacks definitive, objective straightforward solutions (Rittel and Webber, 1973). Climate change research aims to establish a detailed understanding of the effects of increasing carbon concentrations in the atmosphere, and translating those into impacts on environmental, ecological and social systems. Hence, climate change research studies complex systems, initially atmospheric, but also impacts of those changes on other biophysical and socio-ecological systems (and in turn socioeconomic systems) (Rind, 1999; Simon and Schiemer, 2015).

All of these systems are characterised by complexity - there are feedback loops (creating potential tipping points) making simple, linear cause and effect relationships hard to identify. (McGuffie and Henderson-Sellers, 2001; Rind, 1999; Shackley et al., 1998). While climate modelling has developed rapidly, there is still development needed to improve them for both research and decision-making processes (McGuffie and Henderson-Sellers, 2001; Moss et al., 2010).

This complexity means that many aspects of climate change are beyond predictive modelling. Hence, research has to rely on alternative ways of understanding the systems and testing findings that does not rely on traditional prediction and replication (Holm et al., 2013; Mooney et al., 2013; Yeh, 2015). At the same time, human systems involve values, emotions and ethical questions, especially over equity (Mearns and Norton, 2010). The increasing focus on climate change adaptation research, which focuses on the social response to biophysical climate change, highlights the complexity of climate change research (Füssel, 2007; Tol, 2005). As we discuss below, this need to consider the moral and ethical elements of climate change has significant implications for the role of IHEs.

One result of this complexity is the uncertainty that surrounds climate change research (Barnett, 2001). Climate change fits the criteria of post-normal science, in that it is both highly uncertain but with very high stakes (Funtowicz and Ravetz, 1993; Ravetz, 1999). This challenges many of the established processes for doing research by requiring the inclusion of range of other knowledges (e.g. Indigenous/traditional knowledge, local knowledge, policy knowledge) into the traditional scientific process (Yeh, 2015). 
This uncertainty creates challenges for communication as well. Communicating that uncertainty without undermining trust in the research is a challenge (Dessai et al., 2007; Heazle, 2010; Moss, 2007). Developing climate change research that provides straightforward 'solutions' to problems is often impractical. Researchers must balance the need for cutting-edge, theoretical research with demands for applied, 'policy-relevant' science.

The nature of the climate change issue also means that it is highly interdisciplinary (Olsen et al., 2013; Yeh, 2015). Climate change research has to consider the social, economic and political relationships around climate change, as recognised in the IPCC reports. The challenge of interdisciplinary research is well-known (Olsen et al., 2013; Reisinger, 2011;

Yeh, 2015). Existing research silos and increased specialisation have created barriers to collaboration across disciplines. The different approaches of natural and social sciences, in particular provide difficulties in establishing an integrated approach as they often work to different ontologies, epistemologies, and methodologies (Holm et al., 2013; Mooney et al., 2013; Yeh, 2015). Further, the post-normal nature of climate change means that interdisciplinarity also needs to include and engage with a wide range of stakeholders (e.g. policy-makers, managers, decision-makers, industry, communities etc.) as part of the research process, becoming transdisciplinary (Bäckstrand, 2003; O’Brien et al., 2013). However, as we discuss below, overcoming this barrier is key to realising further potentials for climate change research at Universities.

Researchers looking to address these barriers have highlighted how pedagogical approaches can encourage learning and critical thinking about climate change. Bardsley and Bardsley (2007) described constructivist approach to teaching and applied learning to stimulate the analysis of the potential impacts of climate change on systems familiar to high school students, resulting in students discussing possible behavioural and broader personal responses to reduce the impacts of future climate change. Aaron et al. (2013) highlighted that the challenge of climate change offers educators in science, technology, engineering and mathematics (STEM) fruitful opportunities to foster interdisciplinarity, keeping young talented in STEM fields and enhancing multiple literacy for all students. Hence, there are opportunities for IHEs to support climate change action that is sorely needed (Leal Filho 2014), but there are a range of institutional barriers.

\subsection{Institutional Barriers to Climate Change Research: The Challenge for Universities}

Before entering into the empirical elements of the work described in section 3, it is important to acknowledge the fact that the complex, uncertain and interdisciplinary nature of climate change research results in a number of institutional barriers. The complexity can test the resources of research institutions. Climate modelling, for example, requires extremely powerful (and thus expensive) computing technology to create computational models of the climate system. It is notable that most climate models as used by the IPCC have been created by centralised national scientific centres (e.g. NASA, the Met Office and CSIRO).

The need for interdisciplinary approaches also creates barriers. Departments tend to be set up around traditional subjects, although there are increasing efforts to create interdisciplinary research centres. Publishing and funding mechanisms continue to encourage a disciplinary focus. Research funding is generally assigned through a competitive process, with experts peer-reviewing proposals to identify those considered the best. Criteria are highly varied and 
changing, but the expert peer-reviewers are generally senior academics that have highly specialised expertise (Holm et al., 2013). Interdisciplinary projects can struggle to attract support in this environment. Although research funders recognise the need for, and want to encourage interdisciplinary approaches there is little clear guidance on criteria for recognising interdisciplinarity. As Holm et al. (2013, p. 32) note:

“The problem may be that academic research prioritises single-lens in-depth study while multi-lens perspectives need to be assessed against an excellence standard which is not available - or not in use to this point.”

At the same time perceptions of what climate change research 'looks like' might mean that many valuable research areas are not considered - some disciplines or research areas may be overlooked (Holm et al., 2013). The growing focus on climate change adaptation is highlighting how social research into vulnerability, resilience and transitions has a key role to play in responding to climate change, but it is only recently that these might have been seen as climate change science (Moser, 2010).

Importantly, interdiscplinarity is more than making use of another discipline, there must be shared knowledge production and collaboration between disciplines; especially between natural and social sciences (Holm et al., 2013). The challenge for researchers is to build collaborations across these barriers and track down existing expertise, rather than try to 'reinvent the wheel' in an area that is not their field. However, the time and effort required to build collaborations for interdisciplinary and participatory approaches is not always recognised within IHEs (O’Brien et al., 2013; Simon and Schiemer, 2015). The formation of a team is often done informally through social networks, and this process has to compete with the increasing demands put on academics for publishing and securing funding.

These issues are all compounded by the focus on monitoring performance, competition and the neoliberalisation of IHEs, combined with ever restricted funding (Ball, 2012). The 'publish or perish' attitude encourages researchers to take the path of least resistance to getting published to ensure they are competitive, which can discourage interdisciplinary papers and approaches. Move towards focusing on impact as a measure of academic success holds potential for encouraging addressing complex and interdisciplinary issues such as climate change (Simon and Schiemer, 2015). However, an overly managerial approach focused on easily measurably targets could prove problematic (Grant, 2012; Simon and Schiemer, 2015).

Finally, the issue of politics can provide a barrier to climate change research. Although many countries have research bodies that distribute the funding, research is always affected by government priorities and climate change research can be vulnerable to the politics of the day (Simon and Schiemer, 2015). Furthermore, climate change is a highly political issue, and hence climate change research attracts significant scrutiny and attention. This can make research, and particularly communicating research highly challenging (Oreskes, 2004; Pielke Jr, 2002). This may limit both research and its potential impact, as well as putting off potential researchers in the field.

\section{Potentials for climate change research at IHEs}

Despite the challenges discussed above, there is substantial potential for climate change research at IHEs. The United Nations (UN) recently called for IHEs to do more to combat 
climate change. Article 12 of the Paris Agreement directs parties to "enhance climate change education, training, public awareness, public participation and public access to information” (UNFCC, 2015). The Higher Education Sustainability Initiative (HESI), created for the meeting of the 20th Conference of the Parties (COP 20), called for IHEs to improve their teaching, research, community engagement, and information sharing (UN Sustainable Development Platform, 2016). Calls elicited from these highly visible international organizations suggest that there are untapped potentials for IHEs to do more to address climate change.

Rather than merely echoing these calls for more research, teaching and community engagement, this section uses a moral framing of climate change to suggest two

complementary ways that Universities can do more: broadening the definition of research to include non-STEM, and especially ethical, research and the leveraging the wider cultural significance of IHEs. This discussion provides the theoretical basis for analysing the empirical data in the following sections.

Universities are among the world's best institutions for producing research: they house academic presses for books and journals, which are subject to strict peer review and set the standard for knowledge production; they attract significant public and private funding for laboratory and other studies; and they confer doctoral and other advanced degrees. Because academic degrees are the gold standard of research credentials, all research travels through universities, at very least, insofar as doctoral dissertations and other capstone projects for such degree are supervised by faculty at IHEs.

Perhaps one of the most important questions to ask when considering the potential for climate change research impact is to examine what counts as research in the first place: who is qualified to do research on climate change and how should it be done? And as suggested in Section 1.2, criteria for conducting and evaluating interdisciplinary research can serve as a barrier preventing scholars from engaging in such research. There has been a longstanding trend for science, technologies, engineering, and mathematics (or STEM) research to receive more attention and funding when it comes to climate change; for instance, in the United States, STEM fields receive more public funding because of its greater financial returns (Cohen 2016). However, STEM fields are not the only areas of research that are relevant to climate change. The world may currently be witnessing a shift in perspective which recognizes the shortcomings of thinking of climate change solely in terms of technical, scientific or economics problems.

Understanding and characterizing climate change as a moral problem is gaining wider currency in recent years: from to the most recent IPCC Assessment Report (Kolstad et al., 2014) to Pope Francis’ Encyclical, Laudato Si (2015).

In its most recent Assessment Report, the IPCC Working Group 3 on Mitigation of Climate Change included for the first time a climate ethicist, John Broome, as a lead author of Chapter 3: "Social, Economic, and Ethical Concepts and Methods" (Kolstad et al., 2014). The chapter includes moral concepts such as moral responsibility, fairness, intergenerational and distributive justice, well-being, and non-human values. The chapter acknowledges that "ethical judgements of value underlie almost every decision that is connected with climate change, including decisions made by individuals, public and private organizations, governments, and groupings of governments” (Kolstad et al., 2014, 215). The moral concepts 
addressed by this work are for the first time receiving the same degree of publicity as the STEM fields have had over the past several decades. Broome's material is understandably introductory and nowhere reaches the level of sophistication of similar discussions found in non-STEM forums. Nevertheless, his chapter paves the way for more substantial discussions to come.

Notably, Pope Francis has highlighted the significance of thinking beyond the technological and economic aspects of climate change. He appeals for "a new dialogue about how we are shaping the future of our planet” (Pope Francis 2015, 14). He cautions against endorsing the "extreme" positions of "those who doggedly uphold the myth of progress and tell us that ecological problems will solve themselves simply with the application of new technology and without any need for ethical considerations or deep change” (Pope Francis 2015, 60). In other words, Pope Francis' widely read encyclical highlights the distinctly moral dimension of climate change that cannot be addressed by the STEM fields alone.

Moreover, a moral framing of climate change means that IHEs and researchers need to consider their responsibilities in ensuring that their research and its impact have positive effects. This is reflected in the growing interest in Responsible Research and Innovation (RRI) (Burget et al., 2017; Owen et al. 2012). This agenda highlights the need to ensure governance of research and innovation that is inclusive of other stakeholders and ensures that research addresses social and environmental issues (Stilgoe et al. 2013). It strongly reflects the recognition that many areas of research, including climate change, have become 'post normal' science.

There has been debate over whether consideration of the moral or axiological aspects around environmental issues make any substantial difference in the outcome of policies fundamental to research having impact (Norton 1991; Stenmark, 2002). However, Stenmark (2002) shows how policy outcomes often vary widely depending on whether one adopts an anthrocentric, biocentric, or ecocentric axiological position. Similarly, Kassiola (2003) shows that if underlying social values and their byproducts - e.g., the "ceaseless material consumption and the resulting overconsumption producing depletion of natural resources and environmental pollution" (Kassiola, 2003, 10) - are left unexamined, then it is possible new policies will unintentionally reproduce those values, treating the symptoms rather than the roots sources of our environmental problems.

For this reason, philosophy, and more specifically, moral inquiry, is an important tool for analyzing climate change mitigation and adaptation strategies. Universities are already centers for different departments and disciplines that conduct research into these areas in their own ways, but there is untapped potential for these disciplines to come together to fully address the multidimensional challenges of climate change.

\subsection{Wider Cultural Significance of IHEs}

Taking this consideration of moral responsibility further, aside from research and teaching, there is also potential for universities to leverage their position of cultural and social significance to help with climate change mitigation and adaptation efforts. Such institutions often have guiding mission statement that are explicit about their melioristic aims: promoting truths, improving the community, bettering the world for future generations, promoting ethical decision-making skills, and, most recently, goals regarding sustainability. These goals 
necessarily transcend practices found within classrooms and laboratories, and extend to the entire university or college community, as well as the larger communities within which universities find themselves.

Because of their social position and widely recognized cultural role, universities often possess a kind of moral authority when they take action. This authority is amplified when multiple institutions join efforts behind a common aim. Such networking is particularly important for addressing collective action problems such as climate change, in which no one agent or institution can do much to better or worsen the problem on its own. Two recent examples of this networking are the Higher Education Sustainability Initiative (HESI) and the Fossil Fuel Divestment movement.

The HESI was developed in preparation for COP 20+ in Rio in 2012, so although the initiative is committed to sustainability more generally, climate change is certainly part of its scope. The vast majority of the 300+ different organizations across nearly 50 countries are universities/IHEs. The goals of members include providing leadership in sustainability initiatives and sharing information with other member organizations. The potential impact of these organizations grows as more institutions join, not just because more resources can be shared, but because of the symbolic effect of such commitment.

Similarly, the Fossil Free movement had attracted US\$3.4 trillion in divestments (Fossil Free, 2015). Many divesting institutions are IHEs. but the effects are not solely financial but also moral and symbolic; similar to other divestment movements, most notably, the South-African anti-apartheid movement (Massie, 1997). Some insist that divestment makes financial sense for schools wishing to maintain good return to divest in addition to the moral sense (Dorsey, 2014). Such mobilization, whether through networks of more direct action, involves experimenting in new forms of political responsibility, which can be helpful in combating combat structural injustices such as climate change (Godoy, 2017).

Finally, IHEs also have political influence on governments, most likely because of their lobbying power as an industry. This is especially true when IHEs join efforts. Former Secretary of Education and Governor of Tennessee admitted:

"If five or six or eight of those [college] presidents say, "Senator Alexander, may we have a 30-minute appointment with you while you're home next month?”, I'll do it in a minute. So will every other senator.” (Dancy and Laitinen, 2015).

Hence, the political nature of climate change is not only a barrier, as noted above, but also an opportunity for researchers and Universities to show leadership on climate change action.

This discussion highlights both barriers and potential avenues for climate change research at universities. However, addressing these challenges and tapping into the potential on the ground is not straightforward. The next section describes an empirical study to better understand these challenges and opportunities, to allow for a discussion of potential actions for Universities and researchers.

\section{Barriers to implementing climate change research at universities: an empirical study}

Previous work has focused on the relations between universities and climate change (Leal Filho 2010), but many gaps still exist. In order to more specifically identify the extent to which some barriers are preventing the implementation of climate change research at 
universities, an on-line survey was performed involving the administration of universities. This section contains an overview of the empirical components of the work

\subsection{Methods}

An online survey was carried out from $11^{\text {th }}$ January to $11^{\text {th }}$ February 2017 using Google Forms. The survey aimed to characterise the current status of climate change research and development activities, degree of awareness and integration, as well as the perceived barriers at IHE. The survey instrument was composed of 13 questions (seven closed questions and six open questions) and structured in a way that it could gather information on the degree of priority given to climate change research, the resources made available to it, its strategic positioning at the university and the extent to which climate issues are being taught. The questionnaire survey was pre-tested by a panel of researchers from different R\&D areas within sustainability at universities. A copy of the survey can be found in the Supplementary Information.

The survey was disseminated via email (two calls 15 days apart) to the following groups: rectors and office managers of universities participant in the Green Sustainability Metrics 2016; authors with more than 4 publications on the subject "sustainability at universities" in the Web of Science between 2007-2016; participants in the World Symposium on Sustainable Development at Universities, held in September 2016 at the Massachusetts Institute Technology in the United States of America. These covered 48 countries and 5 continents (total of 1200 email addresses).

Statistical analyses was performed on the data collected (percentages and frequencies, for closed questions). Data from open questions were analysed by content analysis (categories were ascertained) and subsequently quantified as percentages. A total of 82 responses were received and analysed. Even though numerically low (7\% response rate), this data is greatly representative and of significance in the context of the population to which it was sent (i.e. worldwide top authors and science/research administrators in IHE in the topic of sustainability at universities).

In terms of methodological limitations, the study could have been complemented with indepth interviews to experts, in order to have a deeper understanding of the barriers, potential and actions when implementing climate change research at Universities. Such a task could be performed in a following study. However, this research shows important attributes concerning relevance and replicability. Due to their still early stage of development, disciplines such as education for sustainable development, climate science, sustainability in higher education, among others, are fertile ground for the application of similar methodologies to the one here employed.

\subsection{Results}

A little over half of the respondents (54\%) expressed the view that his/her university had a climate change research unit or department. The approach to climate change research was perceived by most respondents (67\%) to be inter, multi-, trans-disciplinary and/or cross sectoral (but 33\%, considered it not to be so).

Within the surveyed IHEs, the current top climate change research areas (Table 1) were (i) water (adaptation, 46\%), (ii) energy (mitigation, 41\%, and adaptation, 40\%), (iii) agriculture 
(mitigation, $37 \%$, and adaptation, 43\%), (iv) forestry and biodiversity (adaptation, 40\%) and (v) climate disaster risk management (37\%) (Table 1). Other climate significant change research areas mentioned were climate literacy \& education and climate change communication (28\% and 27\%, respectively), health adaptation (23\%), coastal adaptation (21\%), transport sector (mitigation, 17\%), migration and climate refugees (15\%), climate ethics and justice (11\%), and also paleoclimatology, climatology and modeling (9\%) and geoengineering (7\%). Minor research areas in climate change research were finance, economy and business (4\%), building design and construction (2\%), ocean and atmosphere interactions (1\%), faith and climate change (1\%), awareness and climate change (1\%), data digitalization and climate change (1\%) and integrated cross-sectoral adaptations (1\%).

Table 1 Top research areas in climate change

\begin{tabular}{|l|l|l|}
\hline & Adaptation & Mitigation \\
\hline Water & 46 & \\
\hline Energy & 40 & 41 \\
\hline Agriculture & 43 & 37 \\
\hline Forestry and Biodiversity & 40 & \\
\hline Coastal & 21 & \\
\hline Health & 23 & \\
\hline Transport & & 17 \\
\hline $\begin{array}{l}\text { Climate disaster risk } \\
\text { management }\end{array}$ & 37 & \\
\hline Climate literacy and education & 28 & \\
\hline $\begin{array}{l}\text { Climate change } \\
\text { communication }\end{array}$ & 27 & \\
\hline Migration and climate refugees & 15 & \\
\hline Climate Ethics and justice & 11 & \\
\hline Paleoclimatology & 7 & \\
\hline Climatology and modeling & 7 & \\
\hline $\begin{array}{l}\text { Finance, economy and } \\
\text { business }\end{array}$ & 4 \\
\hline
\end{tabular}

Research in climate change was perceived by the vast majority of the respondents to likely gain relevance in the future (96\%; against $4 \%$ who expressed that it would likely lose relevance). Among the research fields that were expected to gain relevance in the future, $19 \%$ suggested adaptation in general compared to $11 \%$ for mitigation in general, however many respondents focused on specific sectors. The main sectors identified by the respondents to likely gain relevance (Figure 1) were agriculture (adaptation and mitigation), water (adaptation and mitigation) and energy (adaptation and mitigation), all identified by $16 \%$ of respondents, with disaster risk management identified by 14\% (Figure 1). The areas of biodiversity (ecosystems and forestry), policy and education were perceived as gaining relevance, respectively, by $11 \%, 10 \%$ and $9 \%$. Communication, sociology of climate change and health relating to climate change were perceived as likely gaining relevance by under $10 \%$ of respondents ( $7 \%, 7 \%$ and $6 \%$, respectively). Other areas of minor relevance also referred to were: finance (4\%), carbon charging, coastal adaptation, ocean physics, governance (all 2\%) and carbon sequestration, transport, justice, technology development, modeling, data platforms, outreach and multidisciplinary research (all 1\%). 
Migration \& climate refugees

$$
\begin{array}{r}
\text { Sociology } \\
\text { Health }
\end{array}
$$

Communication

Education

Policy

Disaster risk management

Agriculture

Energy

Water

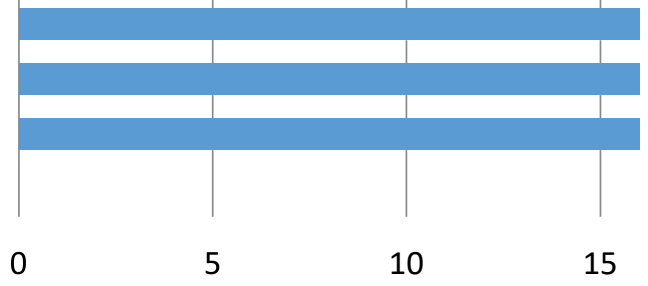

Figure 1 Main fields of Climate change research likely to gain relevance

Most of the respondents answered that none of the identified research areas was likely to lose relevance in the future (32\%), although some had no opinion/were not sure (9\%) (Figure 2). However, some research fields were thought to be more likely to lose relevance in the future, including climate policy (7\% of the respondents), geoengineering, ethics, justice, mitigation in general (all 5\%), migration \& climate refugees, coastal sector (both 4\%), energy mitigation, the health sector and communication (all 2\%). Furthermore, $1 \%$ of the respondents suggested that agriculture adaptation, disaster and risk management, transport, industrial pollution and waste treatment would likely lose relevance, as climate change research fields, presumably reflecting the small number of people that though climate change would lose relevance in general. 

communicating or disseminating results of their research on climate change; only $46 \%$ stated that their university had such a strategy or policy. Additionally, most university rectories'/administrations' did not have low carbon instruments/strategies and policies for climate change mitigation and adaptation (58\%), compared to $42 \%$ that did.

The main barrier to climate change research identified by the respondents at their universities was mainly the "lack of funds" (51\%) (Figure 3), reflecting the increasingly limited funding for IHEs generally in many parts of the world. Some respondents also indicated "administrative and management issues", the "lack of infrastructure" (10\%, in both cases), and the "lack of equipment" (5\%) as barriers to climate change research (all of which are likely to be, at least partly, related to lack of funds). Interestingly, the "lack of experts" (teachers and or researchers) was pointed out by $17 \%$ and lack of knowledge on the topic was identified by $5 \%$ of the respondents as another barrier to climate change research, perhaps suggesting a shortage of climate change specific talent, likely related to the lack of capacity building noted earlier in the results. This is an issue not addressed in the literature directly but perhaps reflecting the lack of interdisciplinary researchers and. 
The "lack of interest in the topic", "unawareness of the importance of climate change" (by lecturers and researchers, but more importantly by the "higher positions in IHE" and by the "university management") were also perceived by $12 \%$ the respondents (in both cases) as barriers to climate change research, reflecting the institutional barriers discussed above. Also in line with these, "university culture" was mentioned as a barrier by $10 \%$ of the respondents due to a variety of factors that inhibited academics to research and publish (e.g. "research is still largely undervalued in the evaluation system”).

The absence of a cross-program approach "policy and framework for CC" and the "lack of connectivity within the university units (groups, people)" was also referred to by $6 \%$ and $5 \%$ of the respondents, respectively. Similarly, the complex nature of climate change and the

inter-and trans-disciplinary nature of $\mathrm{CC}$ research was also pointed out as a barrier by $6 \%$ of the respondents (e.g. "monodisciplinarism appears easier" and "the trans-disciplinarity of CC research is a challenge”). Again, this reflects the discussion of barriers above.

In $4 \%$ of the cases, political agendas above the university level (i.e. Ministries, national agencies) were also identifies as strong barriers to CC research, e.g. as this issue "was not a priority in terms of research politics and agendas" or "climate change issues were led by national agencies and ministries and not universities”, perhaps highlighting the political nature of the issue in some places.

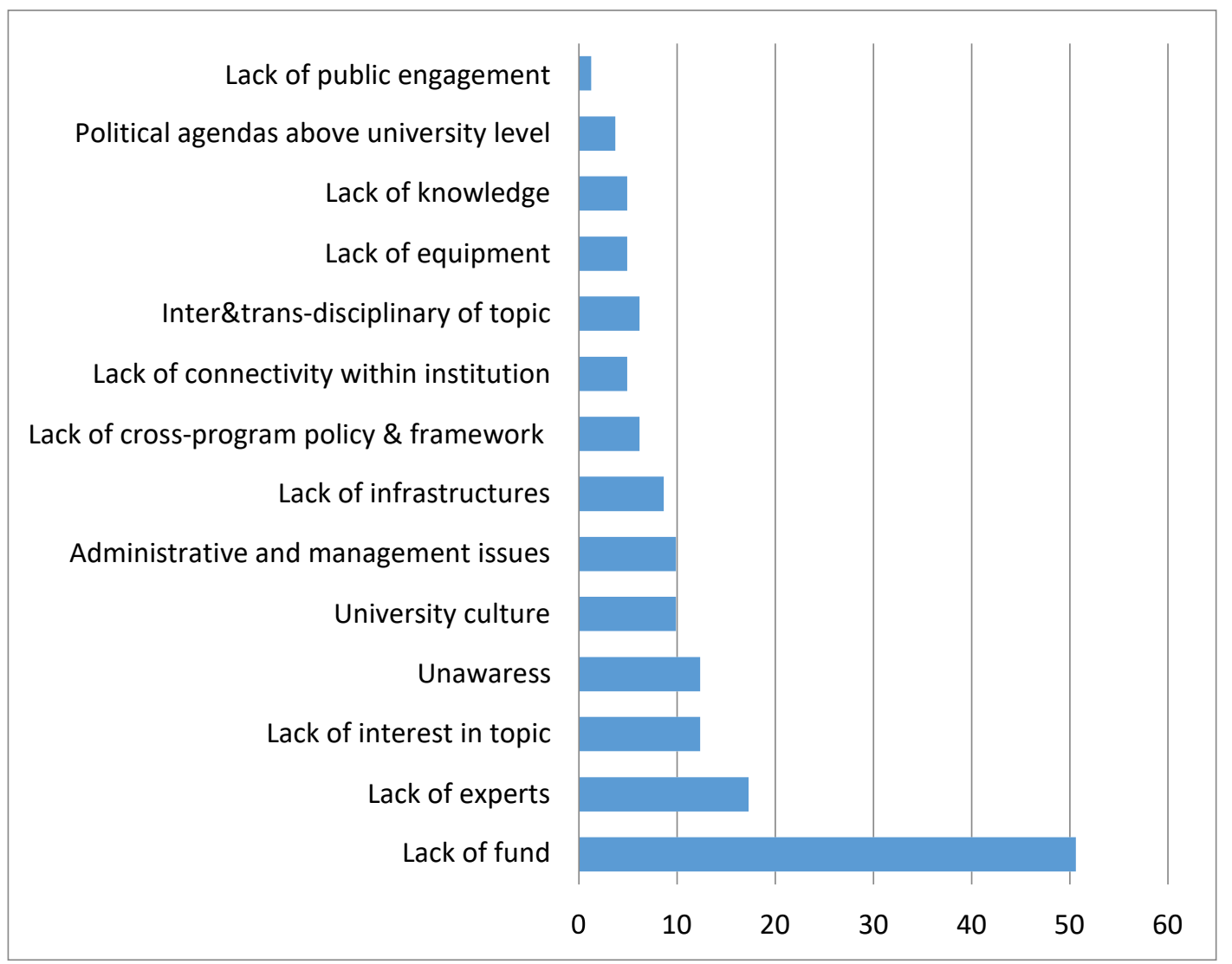

Figure 3 Barriers for climate change research perceived at universities.

The empirical data suggest that climate change research is likely to be of growing importance, especially in particular sectors. However, it also supported the argument that there was significant untapped potential in IHEs, with only around half having strategies around teaching, capacity development, communication and action within the institution. 
Crucially, many of the barriers highlighted in the discussion above were borne out by the empirical work. Although lack of funds was the main barrier highlighted (a common feature of challenges faced by IHEs), the complex and interdisciplinary nature of the research clearly challenged IHEs. Notably, a lack of expertise was highlighted as important. Although climate change has been a significant issue for decades, it seems that research is still struggling to fill the knowledge and expertise gap.

\section{Moving forward}

This review and empirical analysis of barriers to climate change research and the potential of IHEs suggests concrete strategies and guidelines that universities and other IHE's can employ to enhance their roles in addressing climate change. In particular, considering a moral responsibility framing of climate change highlights several recommendations that could support climate change research in IHEs

\subsection{Promoting a Broader Perspective for Climate Change Research}

Climate science is still an ill-defined term. Climate (change) relevant science encompasses much more than climatology, and climate change research, in general, as discussed in Section 2.1 extends beyond the STEM fields to the social sciences, philosophies and humanities. As seen in the survey results, climate-relevant research spans multiple sectors, including the water-energy-land use nexus, health, education and communication, ethics and justice, finance, economics and business. Thus, universities have the unique role to push for wider dialogue, recognizing diverse approaches and forms of research to enrich the climate change discussion, and, beyond that, contribute to concrete solutions.

Climate-relevant research can also be conceptualized more broadly to foster crossfertilization with the highly dynamic field of sustainability science (Hugé et al., 2016). Many universities have embarked on action plans towards the implementation of and support for sustainability science to address the pressing need for sustainable (and equitable) development. This creates opportunities to address climate change issues in a novel and innovative way. In order to understand and develop actions regarding climate change, multiple types of knowledge need to be acknowledged. These include: (i) diagnostic knowledge (with regard to the causes leading to climate change); (ii) explanatory knowledge (with regard to the interactions between social activities and sustainability impacts); (iii) orientation knowledge (with regard to normative justification arguments); (iv) knowledge for action (with regard to finding solutions to 'un-sustainable' situations) (Wooltorton et al., 2015). Knowledge that aims at addressing climate change needs to analyze a system's deeper-lying structures, (diagnostic and explanatory knowledge), it needs to project into the future (orientation knowledge), it needs to assess the impact of decisions (explanatory, orientation and action knowledge), and it has to lead to new strategies for solutions (knowledge for action) (Hugé et al., 2016; Waas et al., 2010). Such knowledge requires the participation of different disciplines, and though more difficult to generate, creates the potential for more lasting impacts.

\subsection{Re-structuring Research and Outreach}

This discussion also highlights that engaging with climate change as a moral issue means engaging beyond academia, as noted in the RRI literature (Burget et al., 2017; Stilgoe et al. 2013). The types of knowledge envisioned necessarily call for an inter-disciplinary and trans- 
disciplinary approach. However, research is still too often discipline-oriented rather than problem/issue-oriented. In many cases, research takes place in silos both in terms of departments within the academe, and in terms of the academe as an actor in a larger community of stakeholders. This can largely be influenced by the incentive structure for advanced studies and research. Thus, career evaluation criteria may end up discouraging inter- and trans-disciplinary work, particularly for young researchers seeking tenure.

Universities can address this challenge by re-structuring career evaluation criteria to duly acknowledge inter- and trans-disciplinary initiatives and achievements.

On a more organizational/administrative level, IHE's can work towards developing and funding inter-disciplinary hubs or research centers on climate change to facilitate dialogue and coordination across the different disciplines within the university, and to actively work on establishing linkages with external stakeholders. These hubs can appoint research and administrative coordinators for drafting and managing inter- and trans-disciplinary projects with regard to climate change, thus lowering the barrier for those who fear that collaborative work might take more time and effort. Such hubs can also house and stimulate interdisciplinary Master and PhD thesis projects, and fund pilot studies focusing on climate change in an inter- and trans-disciplinary context.

Additionally, only $42 \%$ of the administrations represented in the survey have low carbon instruments/strategies and policies for climate change mitigation and adaptation. Here we find significant space to promote the joint creation of strategies and policies in climate change research and campus operations at the university level, through hubs and centers created for this purpose.

\subsection{Re-structuring Teaching}

Teaching is a central mission of IHEs: teaching students the intricacies of multidimensional climate change issues and teaching them methods and tools to address complex inter- and transdisciplinary problems is essential to foster systems thinking and to conduct policyrelevant research.

In our survey, $44 \%$ of the respondents in the online survey stated that an inter-, multi-, transdisciplinary and/or a cross-sectoral approach to climate change was absent from their curricula, and that $70 \%$ did not have a policy nor a plan for capacity building of teachers. This indicates a gap between what is deemed desirable and necessary regarding climate change teaching \& literacy, and what is happening 'on the ground'. This situation probably reflects both the pervasive under-valuation of teaching compared to research output (e.g. publications), and the intrinsic difficulties of teaching complex matters crossing disciplinary boundaries. In turn, this reflects the lack of expertise highlighted as a barrier to climate change research in the survey.

There are several options for IHE's to act upon this. Grant mechanisms can be expanded to include not just projects for research but also projects for capacity-building and even for interdisciplinary climate change-focused scholarships. A climate change professorship/research chair can be established. Common climate science courses can be developed across curricula, and cross-fertilization can be encouraged by allowing students to select elective courses in other faculties to hone interdisciplinary reflexes when dealing with 
'wicked' climate change issues (Morgado et al., 2017). This will, in time, help overcome expertise shortages in climate change research and teaching.

\subsection{Promoting Communication, Engagement and Networking}

As already discussed, IHE's have the potential to generate multiple types of knowledge which can all serve as input to evidence-informed decision-making (Rose, 2014, Hugé et al., 2016). IHE's can promote more robust solutions and policies by helping clarify complex systems, broadening the climate change debate, striving to characterize and address multiple uncertainties, targeting key priorities of communities and funders, and connecting disciplines and stakeholders. However, the potential significance of universities in catalysing action will not be realized without stronger communication and engagement strategies across different stakeholders. The results presented here show that only $46 \%$ of the survey respondents had a strategy or policy to communicate or disseminate climate change research.

To be effective, engagement of non-academic actors to deal with the complexity of climate change should be more systematic. Such engagement must also engender dialogue rather than a one-way dissemination of results, especially since climate change is a highly politicized issue (Morgan, 2017). Co-creation of knowledge should be encouraged, e.g. by way of societal peer review rather than just academic peer review, and IHE's should provide incentives for researchers who are able to bridge stakeholders. Generating knowledge for action means crossing the gap from research into outreach, i.e. actually implementing the solutions recommended, and establishing a mechanism for continued monitoring and evaluation. Furthermore, the innovation potential of climate change research also engenders the inclusion and development of entrepreneurs and startups, creating the need for participation of technology transfer offices at universities.

Inspiration can be drawn from the vast body of literature and experience regarding education for sustainable development (e.g. Annan-Diab \& Molinari, 2017). Academic change agents can contribute to climate change-related research at various levels by engaging in different ways and by promoting different kinds of formal and non-formal learning. Van Poeck et al. (2017) identify different types of change agents based on their level of involvement vs. detachment, and based on their open-ended vs. instrumental objectives.

Furthermore, as noted in the discussion, the influence of IHE's in their local and regional communities can be further strengthened through using networks to leverage their positions. These networks are key to IHE involvement in challenging moral issues, such as climate change, as they mobilise collective action. In addition to HESI and the Fossil Free movement noted above, the existence of highly visible international organizations and networks, such as the American College \& University Presidents Climate Commitment (ACUPCC), the International Sustainable Development Research Society (ISDRS), among others, suggest the potential for further development of similar networking initiatives. For example, ACUPCC signatories, which are around 600, commit to measure and report their greenhouse gas emissions, take immediate actions to reduce them, and develop and implement a plan to go climate neutral. The ISDRS organises yearly conferences, and HESI has over 300 signatories and accounts for more than one-third of all the voluntary commitments that came out of Rio +20 . 
Therefore, there is potential for IHE to deepen their commitment in terms of climate change to diversify and interlink existing networks, to combine the strengths of overarching networks, and/or to create more thematic networks (e.g. on climate-smart agriculture; on lowcarbon technology; on climate change commitments on campus; on nature-based solutions; on climate ethics; on climate change training; etc.).

This discussion has shown that there is much space for moving forward when implementing climate change research at universities. The main recommendations developed from the present study are the following:

- The need to promote inter-disciplinary and trans-disciplinary approaches in research, including in new or existing journals, through the recognition of broader approaches and definition of climate change research. Greater recognition and acceptance of inter- and trans- disciplinary research in IHEs and journals (resulting in well-known and high impact factors journals). This will require both IHEs and existing journal editorial boards to challenge well-established disciplinary structures;

- Work towards developing inter- and trans-disciplinary hubs on climate change in all dimensions of IHEs to facilitate collective actions. This could include: (i) promoting the joint creation of strategies and policies in climate change research and campus operations at the university level; (ii) develop plans for capacity building of teachers; (iii) strengthen communication and engagement strategies across different stakeholders, where co-creation of knowledge among the various actors involved should be encouraged.

Crucially, it is important that systematic, institutional approaches are used to implement these recommendations as opposed to ad hoc ones, as is largely the case today.

\section{Conclusions}

As centres of research and teaching, higher education institutions are often in a position to significantly contribute to current climate change mitigation and adaptation efforts. As this paper has shown, there are a number of barriers of various natures, which prevent them from engaging in effective climate change research. In order to overcome them, there is a need to better communicate the value of research efforts on climate change mitigation and adaptation. It is not sufficient for researchers to simply perform research: their outputs should be more widely communicated. Researchers at universities ought to move away from narrowly focusing on restricting access to research results to specialist journals, and more towards using research findings to influence public discussions about climate change e.g. through the media, policy networks and to interested communities. This will need researchers to develop new skills, which will need to be supported by universities. Finally, climate change communication needs to be placed in the context of wider aspects of climate change research. Future studies will need to investigate could be institutional research on climate change adaptation, integration of matters related to climate change in the curriculum, or the perceptions of students and staff on climate change mitigation and adaptation. 


\section{References}

Aaron, M. M., Brian, W. O., Ryan, D. S., 2013. Gerald, R. U., Aklilu, Z. Promoting interdisciplinarity through climate change education. Nature Climate Change. 3,713-716, doi:10.1038/nclimate1844

Annan-Diab, F. \& Molinari, C. 2017. Interdisciplinarity: practical solution for advancing education for sustainability and the Sustainable Development Goals. International Journal of Management Education 15: 73-83.

Bäckstrand, K., 2003. Civic Science for Sustainability: Reframing the Role of Experts, Policy-Makers and Citizens in Environmental Governance. Glob. Environ. Polit. 3, 24-41. doi:10.1162/152638003322757916

Ball, S.J., 2012. Performativity, Commodification and Commitment: An I-Spy Guide to the Neoliberal University. Br. J. Educ. Stud. 60, 17-28. doi:10.1080/00071005.2011.650940

Bardsley, D. K., Bardsley, A. M., 2007. A Constructivist Approach to Climate Change Teaching and Learning. Geographical Research.45, 29-339. doi:10.1111/j.17455871.2007.00472.

Barnett, J., 2001. Adapting to Climate Change in Pacific Island Countries: The Problem of Uncertainty. World Dev. 29, 977-993. doi:10.1016/S0305-750X(01)00022-5

Burget, M., Bardone, E., Pedaste, M., 2017. Definitions and Conceptual Dimensions of Responsible Research and Innovation: A Literature Review. Sci. Eng. Ethics 23, 1-19. doi:10.1007/s11948-016-9782-1

Cohen P, 2016. A rising call to promote STEM education and cut liberal arts funding. The New York Times. 21 February. Available at http://www.nytimes.com/2016/02/22/business/arising-call-to-promote-stem-education-and-cut-liberal-arts-funding.html. Accessed 1

November 2016.

Dancy K, A Laitinen, 2015. Visualizing the higher education industry. New America. Available at: https://www.newamerica.org/education-policy/edcentral/the-higher-educationindustry/. Accessed 5 November 2016.

Dessai, S., O’Brien, K., Hulme, M., 2007. Editorial: On uncertainty and climate change. Glob. Environ. Chang. 17, 1-3. doi:10.1016/j.gloenvcha.2006.12.001

Dorsey, E, 2014, Yes: they should divest for both financial and moral reasons. Wall Street Journal. 23 November. Available at: http://www.wsj.com/articles/should-endowments-divesttheir-holdings-in-fossil-fuels-1416779351. Accessed on 2 November 2016.

Fossil Free, 2015. Divestment commitments pass the \$3.4 trillion mark at COP21. Available at: http://gofossilfree.org/press-release/divestment-commitments-pass-the-3-4-trillion-markat-cop21/ Accessed 11 March 2015.

Funtowicz, S.O., Ravetz, J.R., 1993. Science for the post-normal age. Futures 25, 739-755. doi:10.1016/0016-3287(93)90022-L

Füssel, H.M., 2007. Adaptation planning for climate change: Concepts, assessment approaches, and key lessons. Sustain. Sci. 2, 265-275. doi:10.1007/s11625-007-0032-y 
Godoy E.S., 2017. Going fossil free: a lesson in climate activism and political responsibility” in Climate Change Research at Universities: Addressing the Mitigation and Adaptation Challenges, ed. Walter Leal Filho. Springer: Berlin, in press.

Grant, W.J., 2012. The "impact” of research carries weight (but ripples matter more). The Conversation. Available at: http://theconversation.com/the-impact-of-research-carriesweight-but-ripples-matter-more-6820

Heazle, M., 2010. Uncertainty in policy making. Values and evidence in complex decisions. Earthscan, London.

Hugé, J., Block, T., Waas, T., Wright, T., Dahdouh-Guebas, F. 2016. How to walk the talk? Developing actions for sustainability in academic research. Journal of Cleaner Production 137: 83-92.

Holm, P., Goodsite, M.E., Cloetingh, S., Agnoletti, M., Moldan, B., Lang, D.J., Leemans, R., Moeller, J.O., Buendía, M.P., Pohl, W., Scholz, R.W., Sors, A., Vanheusden, B., Yusoff, K., Zondervan, R., 2013. Collaboration between the natural, social and human sciences in Global Change Research. Environ. Sci. Policy 28, 25-35. doi:10.1016/j.envsci.2012.11.010

Kassiola J, 2003. Can environmental ethics 'solve' environmental problems and save the world? Yes, but first we must recognise the essential normative nature of environmental problems. Environmental Values 12 (4):489-514. doi: 10.3197/096327103129341423

Kolstad C., K. Urama, J. Broome, A. Bruvoll, M. Cariño Olvera, D. Fullerton, C. Gollier, W.M. Hanemann, R. Hassan, F. Jotzo, M.R. Khan, L. Meyer, L. Mundaca, 2014: Social, Economic and Ethical Concepts and Methods. In: Climate Change 2014: Mitigation of Climate Change. Contribution of Working Group III to the Fifth Assessment Report of the Intergovernmental Panel on Climate Change, Edenhofer, O., R. Pichs-Madruga, Y. Sokona, E. Farahani, S. Kadner, K. Seyboth, A. Adler, I. Baum, S. Brunner, P. Eickemeier, B. Kriemann, J. Savolainen, S. Schlömer, C. von Stechow, T. Zwickel, J.C. Minx (eds.). Cambridge, UK: Cambridge University Press.

Leal Filho, W. (Eds). 2010. Universities and Climate Change - Introducing Climate Change at University Programmes. Springer, Berlin.

Leal Filho, W., 2014. Acting now: why more climate change mitigation and adaptation is needed. International Journal of Climate Change Strategies and Management, 6, 4, doi.org/10.1108/IJCCSM-09-2014-0106

Massie, R K, 1997. Loosing the Bonds: The United States and South Africa in the Apartheid Years. New York: Nan A. Talese.

McGuffie, K., Henderson-Sellers, A., 2001. Forty years of numerical climate modelling. Int. J. Climatol. 21, 1067-1109. doi:10.1002/joc.632

Mearns, R., Norton, A. (Eds.), 2010. Social Dimensions of Climate Change: Equity and Vulnerability in a Warming World. The World Bank, Washington, D.C. doi:10.1596/978-08213-7887-8 
Mooney, H.A., Duraiappah, A., Larigauderie, A., 2013. Evolution of natural and social science interactions in global change research programs. Proc. Natl. Acad. Sci. U. S. A. 110, 3665-72. doi:10.1073/pnas.1107484110

Morgado, F., Bacelar-Nicolau, P., Rendon-Von Osten, J., Santos, P., Bacelar-Nicolau, L., Farooq, H., Alves, F., Soares, A., Azeiteiro, U.M., 2017. Assessing University Student Perceptions and Comprehension of Climate Change (Portugal, Mexico and Mozambique). International Journal of Climate Change Strategies and Management. 9(3): 316-36 http://dx.doi.org/10.1108/IJCCSM-08-2016-0123

Morgan, E. A. 2017. The Challenges and Opportunities for Higher Education Institutions at the Science-Policy Interface, in Climate Change Research at Universities: Addressing the Mitigation and Adaptation Challenges, ch. 7, ed. Walter Leal Filho. Springer: Berlin.

Moser, S.C., 2010. Now more than ever: The need for more societally relevant research on vulnerability and adaptation to climate change. Appl. Geogr. 30, 464-474. doi:10.1016/j.apgeog.2009.09.003

Moss, R.H., 2007. Improving information for managing an uncertain future climate. Glob. Environ. Chang. 17, 4-7. doi:10.1016/j.gloenvcha.2006.12.002

Moss, R.H., Edmonds, J.A., Hibbard, K.A., Manning, M.R., Rose, S.K., van Vuuren, D.P., Carter, T.R., Emori, S., Kainuma, M., Kram, T., Meehl, G.A., Mitchell, J.F.B., Nakicenovic, N., Riahi, K., Smith, S.J., Stouffer, R.J., Thomson, A.M., Weyant, J.P., Wilbanks, T.J., 2010. The next generation of scenarios for climate change research and assessment. Nature 463, 747-756.

Norton, B G, 1991. Toward Unity among Environmentalists, Oxford: Oxford University Press.

O’Brien, L., Marzano, M., White, R.M., 2013. “Participatory interdisciplinarity”: Towards the integration of disciplinary diversity with stakeholder engagement for new models of knowledge production. Sci. Public Policy 1-11. doi:10.1093/scipol/scs120

Olsen, D.S., Borlaug, S.B., Klitkou, A., Lyall, C., Yearley, S., 2013. A Better Understanding of Interdisciplinary Research in Climate Change (No. 15/2013). NIFU: Oslo.

Oreskes, N., 2004. Science and public policy: what's proof got to do with it? Environ. Sci. Policy 7, 369-383. doi:10.1016/j.envsci.2004.06.002

Owen, R., Macnaghten, P., Stilgoe, J., 2012. Responsible research and innovation: From science in society to science for society, with society. Sci. Public Policy 39, 751-760. doi:10.1093/scipol/scs093

Pielke Jr, R.A., 2002. Policy, politics and perspective. Nature 416, 2001-2002.

Pope Francis. 2015. Laudato Si’: On Care for Our Common Home [Encyclical]. Available at http://w2.vatican.va/content/francesco/en/encyclicals/documents/papafrancesco_20150524_enciclica-laudato-si.html. Accessed 31 October 2016.

Ravetz, J.R., 1999. What is post-normal science. Futures 31, 647-653. 
Reisinger, A., 2011. Interdisciplinarity: are we there yet? Clim. Change 108, 23-30. doi:10.1007/s10584-011-0108-7

Rind, D., 1999. Complexity and Climate. Science. 284, 105 LP-107.

Rittel, H. W. J., Webber, M. M., 1973. Dilemmas in a general theory of planning. Policy Sciences, 4(2), 155-169.

Rose, D. C., 2014. Five ways to enhance the impact of climate science. Nature Climate Change 4: 522-524. doi:10.1038/nclimate2270

Shackley, S., Young, P., Parkinson, S., 1998. Uncertainty, complexity and concepts of good science in climate change modelling: are GCMs the best tools? Clim. Change 38, 159-205.

Simon, D., Schiemer, F., 2015. Crossing boundaries: Complex systems, transdisciplinarity and applied impact agendas. Curr. Opin. Environ. Sustain. 12, 6-11. doi:10.1016/j.cosust.2014.08.007

Stenmark, M, 2002. The Relevance of Environmental Ethical Theories for Policy Making. Environmental Ethics, Volume 24, Issue 2: 135-148, DOI: 10.5840/enviroethics200224227.

Stilgoe, J., Owen, R., Macnaghten, P., 2013. Developing a framework for responsible innovation. Res. Policy 42, 1568-1580. doi:10.1016/j.respol.2013.05.008

Tol, R., 2005. Adaptation and mitigation: trade-offs in substance and methods. Environ. Sci. Policy 8, 572-578. doi:10.1016/j.envsci.2005.06.011

UNFCC, 2015. Adoption of the Paris Agreement. 12 December. Paris. Available at: https://unfccc.int/resource/docs/2015/cop21/eng/109r01.pdf. Accessed April 4, 2016.United Nations Sustainable Development Platform. 2016. Higher Education Sustainability Initiative. (website) Available at https://sustainabledevelopment.un.org/sdinaction/hesi. Accessed 2 November 2016.

Van Poeck, K. Loessoe, J. \& Block, T. 2017. An exploration of sustainability change agents as facilitators of non-formal learning: mapping a moving and intertwined landscape. Ecology \& Society 22: 33.

Waas, T., Hugé, J., Verbruggen, A. \& Wright, T. 2011. Sustainable development: a bird’s eye view. Sustainability 3: 1637-1661

Wooltorton, S., Wilkinson, A., Horwitz, P., Bahn, S., Redmond, J., Dooley, J., 2015. Sustainability and action research in universities: towards knowledge for organizational transformation. Int. J. Sustain. High. Educ. 16, 424-439.

Yeh, E.T., 2015. “How can experience of local residents be 'knowledge’?” Challenges in interdisciplinary climate change research. Area 34-40. doi:10.1111/area.12189 


\section{Implementing Climate Change Research at Universities: Barriers, Potential and Actions}

\section{Highlights}

- A theoretical and empirical study of barriers to climate change research in universities was conducted.

- Barriers included institutional and capacity issues.

- The need for inter- and transdisciplinary research calls for new approaches to research and teaching.

- The article highlights opportunities to advance climate change research for universities to overcome some of these institutional and capacity barriers. 
Click here to download Data File: Survey for Implementing Climate Change Research at Universities.pdf

Survey Questions
Click here to down

(1)

(1)

.

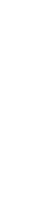
. 